\title{
Rating curve pattern in a compound meandering channel flow
}

\author{
Md. Abdullah Al Amin", ", Md. S. M. Khan², M. R. Kabir ${ }^{3}$, Md. Ashraf-ul-Islam ${ }^{4}$ \\ ${ }^{1}$ Assistant Engineer, Bangladesh Water Development Board, Bangladesh \\ ${ }^{2}$ Dept. of Water Resources Engineering, BUET, Dhaka, Bangladesh \\ ${ }^{3}$ Dept. of Civil Engineering, UAP, Dhaka, Bangladesh \\ ${ }^{4}$ Project Coordinator, RDRS, Dhaka, Bangladesh
}

\section{Email address:}

amin_01buet@yahoo.com(M. A. A. Amin), mostafakhan@wre.buet.ac.bd(M. S. M. Khan), mkabir@uap-bd.edu(M. R. Kabir), ashraf.hiz@gmail.com(M. Ashraf-ul-Islam)

\section{To cite this article:}

Md. Abdullah Al Amin, Md. S. M. Khan, M. R. Kabir, Md. Ashraf-ul-Islam. Rating Curve Pattern in a Compound Meandering Channel Flow. Journal of Water Resources and Ocean Science. Vol. 2, No. 3, 2013, pp. 29-32. doi: 10.11648/j.wros.20130203.11

\begin{abstract}
Most of the river flow in the world can be characterized as compound meandering channel in which the discharge distributions are very complex. Engineers, planners and researchers are highly interested in predicting accurately as well as reliably the quantitative estimates of discharge in a compound meandering channel. A laboratory experiment has been performed in a compound meandering channel with symmetric cross-sections having floodplain width ratio of 1.00 , 1.67, 2.33, 3.00 and depth ratio of $0.20,0.30,0.35,0.40$ using the large-scale open air facility in the Department of Water Resources Engineering, Bangladesh University of Engineering and Technology (BUET), Dhaka, Bangladesh. Point velocity data have been collected using an ADV (Acoustic Doppler Velocity meter) for different depth and width ratio at different locations of a compound meandering channel. Cross-sectional discharge is computed by area velocity method from the observation of velocity profile. The laboratory experiment shows that the rating curve pattern in a compound meandering channel follows the straight curve up to in bank flow and in the out bank flow it is in curvature nature.
\end{abstract}

Keywords: Meandering Channel, Discharge Distribution, Width Ratio, Depth Ratio, Flood plain, ADV

\section{Introduction}

Generally, natural rivers, streams and manmade surface drainage channels often overflow their banks during episodes of high flooding resulting in a huge potential damage to life and property as well as erosion and depositions of sediments. Many rivers have meandering compound channels possessing a main channel, which always carries flow in one or two floodplains, which only carry flow at above bankful stages. It has been established that a strong interaction between the faster moving main channel flow and slower moving floodplain flow takes place in a compound channel. This interaction results in a lateral transfer of a significant amount of longitudinal momentum which affects the discharge distribution in a channel flow. Discharge in a compound meandering channel is strongly governed by interaction between flow in the main channel and that in the floodplain and are different due to prevailing of different hydraulic conditions in the main channel and floodplain flow.
Stage-discharge curve known as rating curve in a compound meandering channel plays an important role in controlling floods, solving a variety of river hydraulics and engineering problems, designing stable channels, revetments and artificial waterways. There are limited reports concerning the stage-discharge relationship in a compound meandering channel. Most of the efforts of [1], [2], [3], [4], [5], [6], [7], [8], [9] and [10] were concentrated on the energy loss, different methods for stage-discharge assessment in the compound meandering sections. The present study is aimed at understanding the phenomenon of rating curve pattern in a compound meandering channel.

\section{Methodology}

The experimental study has been conducted in the open air facility of Water Resources Engineering Department, Bangladesh University of Engineering and Technology (BUET), Dhaka. The experimental setup is shown in the Fig.1 which consists of two parts, the permanent part and the 
temporary part. The permanent part is the experimental facility necessary for the storage and regulation of water circulating through the experimental reach. The temporary part is mainly brick walls which are used to vary the floodplain width for different setups. The experimental reach consists of a $670 \mathrm{~cm}$ long symmetric compound meandering channel, set at constant bed slope $\left(\mathrm{S}_{\mathrm{o}}\right)$ of 0.001845 with fixed bed and banks and sinuosity ratio $\left(\mathrm{S}_{\mathrm{r}}\right)$ of 1.20. Water is drawn by the centrifugal pump of discharge capacity $80 \mathrm{l} / \mathrm{s}$ from the storage reservoir then it discharges into the upstream reservoir and conveys water to the experimental reach through approach channel of $30 \mathrm{~m}$ in length and $3.1 \mathrm{~m}$ in width. To ensure a more smooth flow towards the approach channel guide vanes and tubes are placed between the upstream reservoir and the approach channel which are at right angle to each other. In order to prevent turbulence in the approach channel, PVC pipes (diffuser) are used. The water regulating function of the downstream end is provided by tail gate. The tail gate rotates around a horizontal axis. It is operated to maintain desired water level in the experimental reach. At the end of the experimental channel, water is allowed to flow freely so that backwater has no effect in the experimental reach. Behind the tail gate, the water falls into the stilling basin and passes through a transition flume which allows water for recirculation.

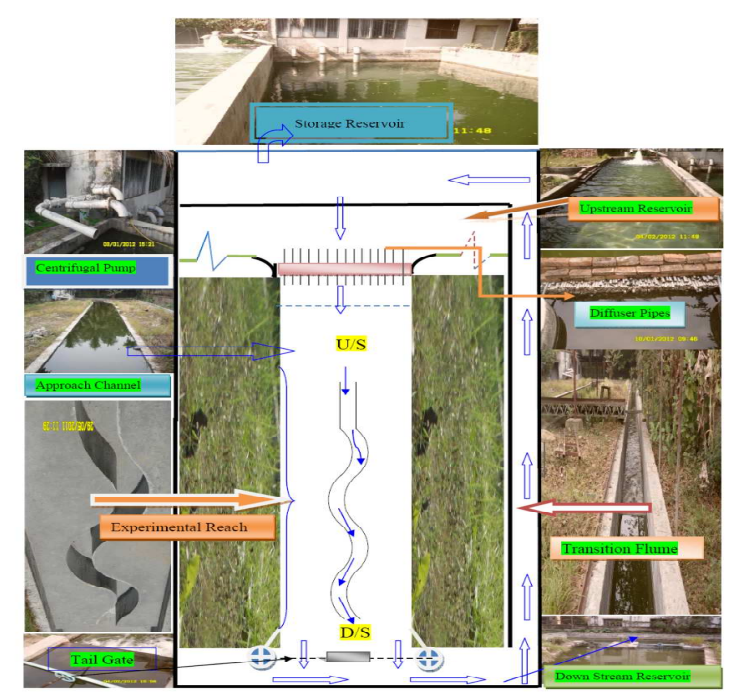

Figure 1. Schematic diagram of the laboratory experimental setup

Experiments were performed for four cases i.e. width ratio $\mathrm{Wr}=1.00,1.67,2.33,3.00$ at four runs i.e. depth ratio $\mathrm{Dr}=$ $0.20,0.30,0.35,0.40$.

Case I: It represents no floodplain condition having width ratio $\mathrm{Wr}=1$ and cross-sectional dimension of the Channel is $45.70 \mathrm{~cm} \times 42 \mathrm{~cm}$.

Case II: It indicates symmetric floodplain width $15.30 \mathrm{~cm}$ having width ratio $\mathrm{Wr}=1.67$. The cross-sectional dimension of the main channel is $45.70 \mathrm{~cm}$ x $24.50 \mathrm{~cm}$, left floodplain $15.30 \mathrm{~cm}$ x $18 \mathrm{~cm}$ and right floodplain $15.30 \mathrm{~cm} \times 18 \mathrm{~cm}$.
Case III: It indicates symmetric floodplain width 30.50 $\mathrm{cm}$ having width ratio $\mathrm{Wr}=2.33$. The cross-sectional dimension of the main channel is $45.70 \mathrm{~cm} \times 24.50 \mathrm{~cm}$, left floodplain $30.50 \mathrm{~cm} \mathrm{x} 18 \mathrm{~cm}$ and right floodplain $30.50 \mathrm{~cm} \mathrm{x}$ $18 \mathrm{~cm}$.

Case IV: It indicates symmetric floodplain width 45.70 $\mathrm{cm}$ having width ratio $\mathrm{Wr}=3.00$. The cross-sectional dimension of the main channel is $45.70 \mathrm{~cm} \mathrm{x} 24.50 \mathrm{~cm}$, left floodplain $45.70 \mathrm{~cm} \mathrm{x} 18 \mathrm{~cm}$ and right floodplain $45.70 \mathrm{~cm} \mathrm{x}$ $18 \mathrm{~cm}$.

Point velocities data have been collected by ADV (Acoustic Doppler Velocity meter) at different locations (upstream clockwise bend, upstream crossover, upstream anticlockwise bend etc) of a compound meandering channel. Each location is divided into 19 zones starting from left floodplain to right floodplain. The main channel is equally divided into nine zones (zone 1 to zone 9), the left floodplain is equally divided into 5 zones (zone 1 to zone 5) and right floodplain is divided into 5 zones (zone 1 to zone 5). The definition sketch of compound meandering channel is shown in Fig. 2 and the experimental run conditions are shown in the table 1 .

Table 1. Experimental run conditions

\begin{tabular}{|c|c|c|c|c|}
\hline Case & $\begin{array}{c}\text { Run } \\
\text { no. }\end{array}$ & $\begin{array}{l}\text { Width } \\
\text { Ratio } \\
\text { (Wr) }\end{array}$ & $\begin{array}{c}\text { Depth } \\
\text { Ratio } \\
\text { (Dr) }\end{array}$ & Location of the Reading \\
\hline \multirow{4}{*}{ I } & 1 & \multirow{4}{*}{1.00} & 0.20 & \multirow{16}{*}{$\begin{array}{l}\text { Velocity reading at } 0.1 \mathrm{H} \text {, } \\
0.2 \mathrm{H}, 0.4 \mathrm{H}, 0.6 \mathrm{H}, 0.8 \mathrm{H} \text { from } \\
\text { the water surface in the main } \\
\text { channel and } 0.1 \mathrm{H}^{\prime}, 0.2 \mathrm{H}^{\prime}, 0.4 \\
\mathrm{H}^{\prime}, 0.6 \mathrm{H}^{\prime}, 0.8 \mathrm{H}^{\prime} \text { from the } \\
\text { water surface in the flood } \\
\text { plain. }\end{array}$} \\
\hline & 2 & & 0.30 & \\
\hline & 3 & & 0.35 & \\
\hline & 4 & & 0.40 & \\
\hline \multirow{4}{*}{ II } & 5 & \multirow{4}{*}{1.67} & 0.20 & \\
\hline & 6 & & 0.30 & \\
\hline & 7 & & 0.35 & \\
\hline & 8 & & 0.40 & \\
\hline \multirow{4}{*}{ III } & 9 & \multirow{4}{*}{2.33} & 0.20 & \\
\hline & 10 & & 0.30 & \\
\hline & 11 & & 0.35 & \\
\hline & 12 & & 0.40 & \\
\hline \multirow{4}{*}{ IV } & 13 & \multirow{4}{*}{3.00} & 0.20 & \\
\hline & 24 & & 0.30 & \\
\hline & 15 & & 0.35 & \\
\hline & 16 & & 0.40 & \\
\hline
\end{tabular}

In each zone $3 \mathrm{D}$ point velocity readings are taken by ADV at five vertical points i.e. $0.1 \mathrm{H}, 0.2 \mathrm{H}, 0.4 \mathrm{H}, 0.6 \mathrm{H}, 0.8 \mathrm{H}$ for main channel and $0.1 \mathrm{H}^{\prime}, 0.2 \mathrm{H}^{\prime}, 0.4 \mathrm{H}^{\prime}, 0.6 \mathrm{H}^{\prime}, 0.8 \mathrm{H}^{\prime}$ for floodplain. Sample of data collection by ADV is shown in the Fig. 3. In each vertical point 60 seconds point velocity readings are taken and average velocity of 60 seconds point velocity is used for plotting the velocity profile. Cross-sectional discharge is calculated by area velocity method from the observation of velocity profile. In this 
method a channel section is subdivided into a number of segments by a number of successive intervals. For all the cross-sections, discharge is calculated separately for the main channel, right and left flood plain; and then total discharge is obtained.

The discharge of the segment is calculated as follows

$$
\Delta \mathrm{Qi}=\Delta \mathrm{Ai} . \mathrm{Ui}
$$

Where $\Delta \mathrm{Qi}$ is the discharge in the ith segment, $\Delta \mathrm{Ai}$ is the cross-sectional area of the ith segment and $\mathrm{Ui}$ is the average velocity at the ith vertical.

The total discharge is computed as

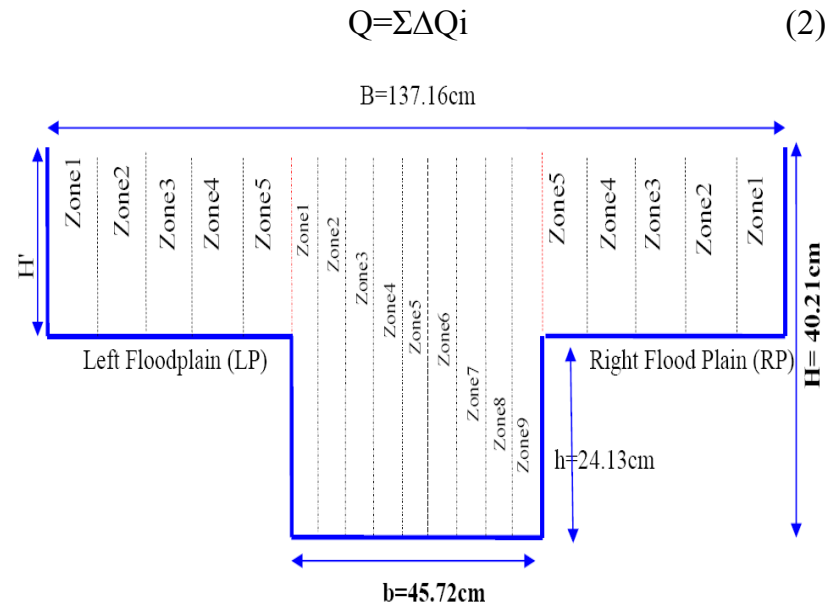

Figure 2. Sketch of the compound meandering channel section

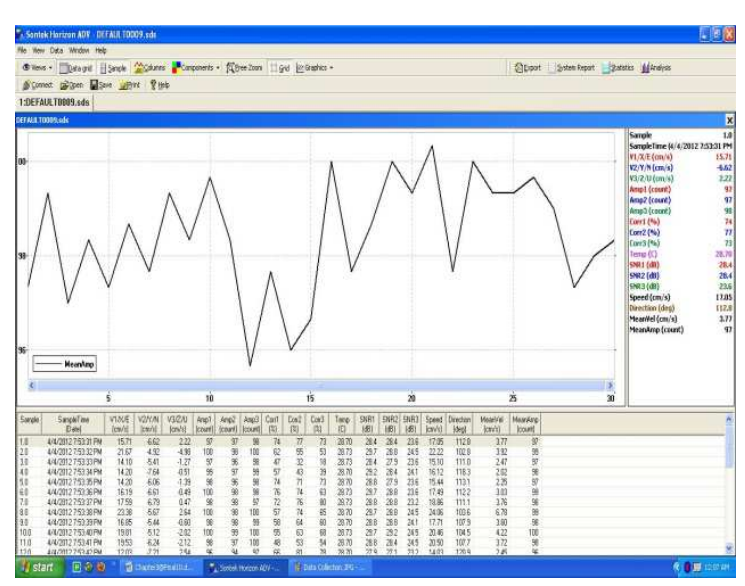

Figure 3. Data collection by $A D V$

\section{Results and Discussions}

Stage discharge curves with varying width ratios at upstream clockwise bend section, upstream cross-over section and upstream anticlockwise bend section are shown in the Fig. 4, Fig. 5 and Fig. 6. In all the cases, discharge increases with the increase of width ratio for the discharge just above the bank level of the main channel. For the discharges just above the bank level, the retarding influence of the flood plain takes its toll on the overall discharge of the channel. As the depth ratio increases, the retarding effect of the floodplain is counter balanced by the increase in greater flow area provided by the floodplain. So for the higher water level (depth ratio), the discharge increases with the increase in depth of flow.

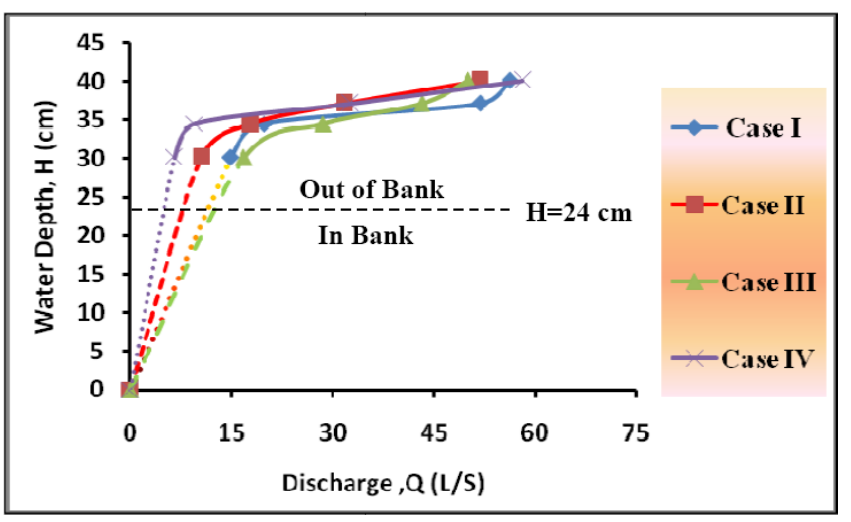

Figure 4. Rating curve at upstream clockwise bend section

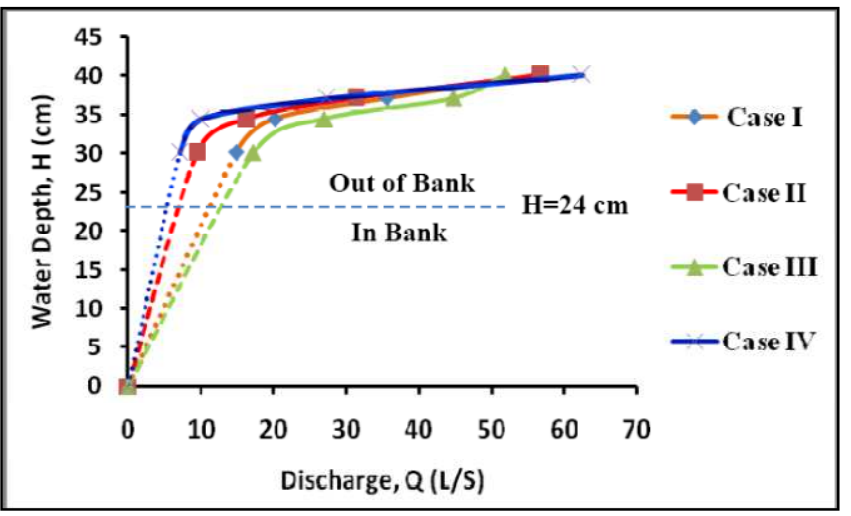

Figure 5. Rating curve at upstream crossover section

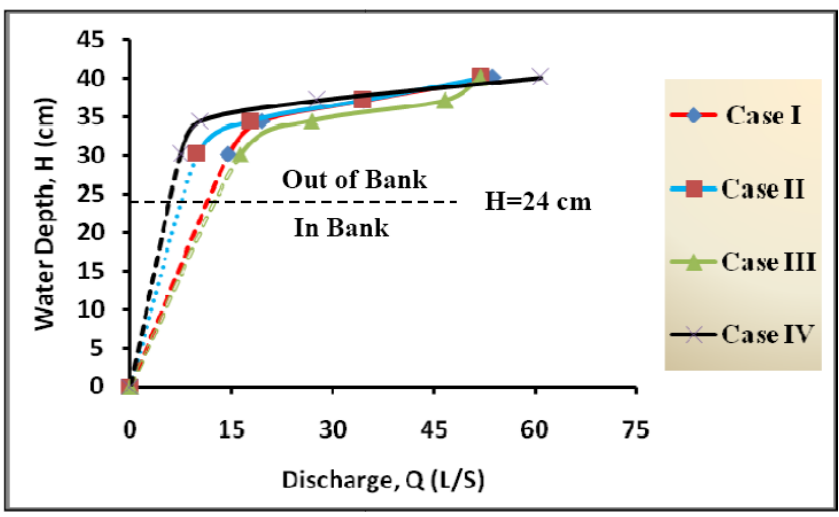

Figure 6. Rating curve at upstream anti-clockwise bend section

\section{Conclusions}

On the basis of present research concerning the rating curve pattern in a compound meandering channel with varying floodplain width the following conclusions are drawn: In a compound meandering channel, discharge increases with the increase of depth ratio and increasing rate of discharge is more at high water depth ratio. Because at low water depth ratio the slow moving flow in the floodplain interact with the fast moving main channel flow intensely 
and considerable momentum exchange takes place. But the intensity of interaction diminishes considerably with the increase of depth ratio. Rating curve pattern in a compound meandering channel follows the straight curve up to in bank flow and in the out bank flow it is in curvature nature.

\section{Acknowledgements}

First of all, the authors are very much thankful to the almighty, Allah for enabling them to complete their work successfully. The authors convey their sincere gratitude to head of the Department of Water Resources Engineering, Bangladesh University of Engineering and Technology, for giving all the facilities needed which helped the authors to reach at culmination of the work successfully.

The authors would like to thank the assistants of Physical Modelling Laboratory of BUET for their dexterous help to complete their laboratory experiment efficiently.

Finally, the authors would like to thank all of their well wishers and colleagues.

\section{Nomenclature}

The following symbols are used in this paper $\Delta \mathrm{Ai}=$ Cross-sectional area of the ith segment $\mathrm{B}=$ top width of compound meandering channel $\mathrm{b}=$ width of main channel

$\mathrm{Dr}=$ depth ratio $(\mathrm{H}-\mathrm{h}) / \mathrm{h}$

$\mathrm{H}=$ total water depth

$\mathrm{H}^{\prime}=$ depth of water above floodplain bed

$\mathrm{h}=$ height of the main channel

$\Delta \mathrm{Qi}=$ discharge in the ith segment

$\mathrm{Q}=$ total discharge

$\mathrm{S}_{\mathrm{o}}=$ bed slope

$\mathrm{S}_{\mathrm{r}}=$ sinuosity ratio

$\mathrm{Ui}=$ average velocity at the ith vertical.

$\mathrm{Wr}=$ width ratio $[\mathrm{B} / \mathrm{b}]$

\section{References}

[1] Al-Romaih, J. S. (1996). "Stage discharge assessment in meandering channels," PhD thesis, Univ. of Bradford, U.K.

[2] Groenhill, R. K., and Sellin, R. H. J. (1993). "Development of a simple method to predict discharge in compound meandering channels." Proc. Institute Civil Engineers, Water, Merit and Energy, 101, Water Board, (March), 37-44.

[3] Muto, Y. (1995). “Turbulent flow in two stage meander chanenls." PhD thesis, Univ. of Bradford, U.K.

[4] Patra, K.C., and Kar, S.K., Bhattacharya.A.K. (2004). "Flow and Velocity Distribution in Meandering Compound Channels." Journal of Hydraulic Engineering, ASCE, Vol. 130, No. 5. 398-411.

[5] Sellin, R. H. J., Ervine, D. A., and Willetts, B. B. (1993). "Behavior of meandering two stage channels." Proc. of Institute Civil Engineers Water Maritime and Energy, 101, (June), Paper No. 10106, 99-111.

[6] Shiono, K., and Muto, Y. (1993). "Secondary flow structure for inbank and overbank flows in trapezoidal meandering channels." Proc., $5^{\text {th }}$ Int. Symp. of Refined Flow Modl. and Turb. Measu., Paris (September), 645-652.

[7] Shiono, K., Muto, Y., Knight, D. W., and Hyde, A. F. L. (1999a). "Energy losses due to secondary flow and turbulence in meandering channels with over bank flow." $J$. Hydraul. Res., 37(5), 641-664.

[8] Toebes, G. H., and Sooky, A. A. (1967). "Hydraulics of meandering rivers with flood plains." J. Waterw. Harbors Div., Am. Soc. Civ. Eng., 93(2), 213-236.

[9] Wark, J. B., and James, C. S. (1994). “An application of new procedure for estimating discharge in meandering overbank flows to field data." 2nd Int. Conf. on River Flood Hydraulics, March 22-25, Wiley, NewYork, 405-414.

[10] Willetts, B. B., and Hardwick, R. I. (1993). "Stage dependency for over bank flow in meandering channels." Proc., Institute of Civil Engineers Water Maritime and Energy, 101, $45-54$. 